For reprint orders, please contact: reprints@futuremedicine.com

\title{
The case for over-the-counter shortwave therapy: safe and effective devices for pain management
}

Ian M Rawe*
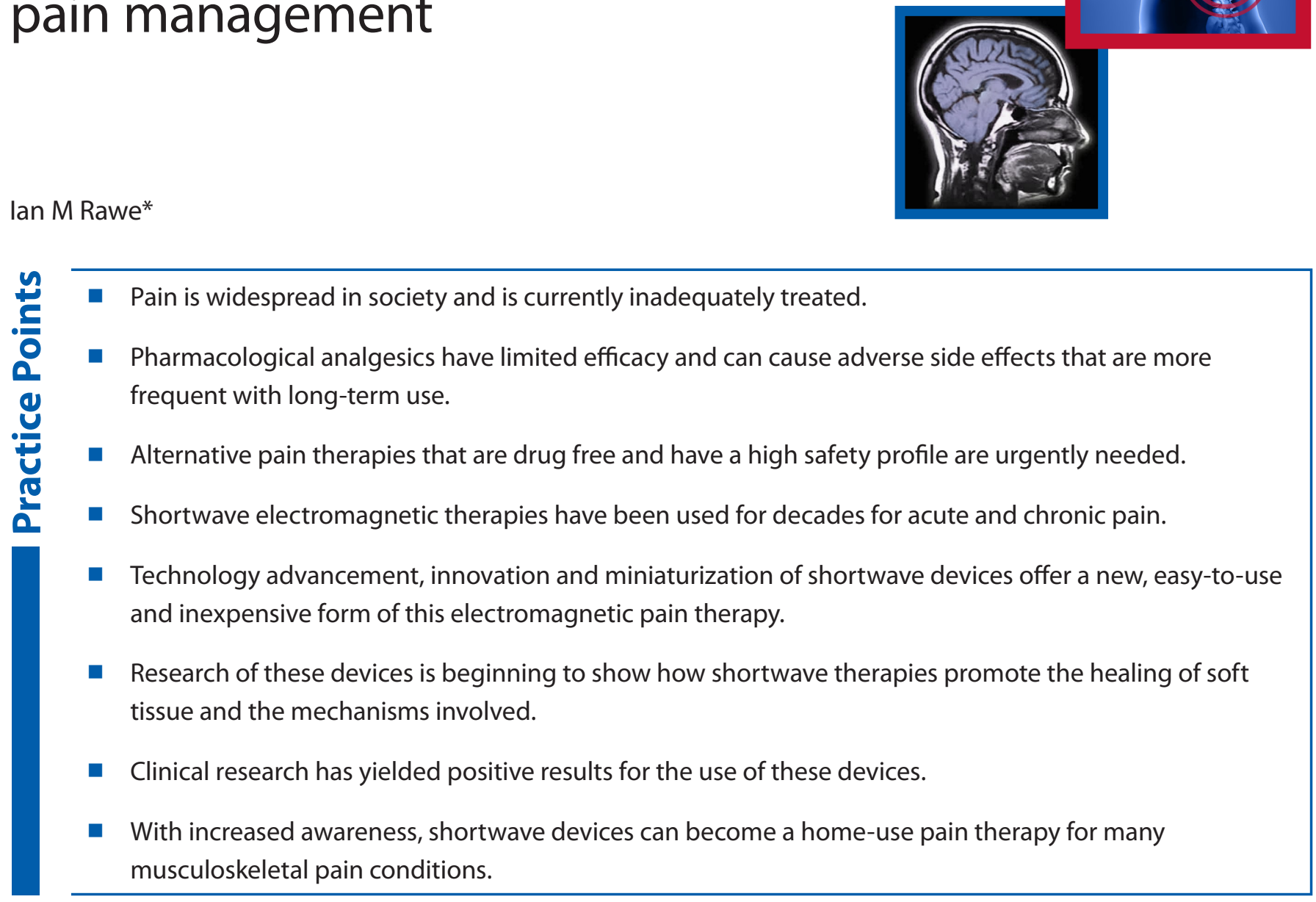

SUMMARY Pulsed shortwave diathermy, an electromagnetic therapy, has been in clinical use for acute and chronic musculoskeletal pain for many decades. Innovation, miniaturization and advances in technology have allowed for the development of a new generation of shortwave devices that deliver a localized, low fixed dose of shortwave therapy. Clinical research has shown that these novel shortwave devices can be used safely in order to reduce acute and chronic pain, as well as the need for pain medications. Their ease of use and safety profile make low-dose shortwave devices an attractive alternative, or adjunct therapy, to pharmacological-based pain therapies.

Pain management is a very important healthcare issue, both because of the negative impact pain has on patient quality of life, and also the significant associated healthcare costs involved in pain management. The effect of unresolved pain on quality of life is high, and constant pain results in a significantly increased risk of depression and suicide [1,2]. Studies have demonstrated the wide prevalence of both acute and chronic pain in society, with estimates of up to 100 million people suffering from chronic pain annually in the USA [3]. The assessment on the costs

*Clinical Research, BioElectronics Corporation, 4539 Metropolitan Court, Frederick, MD 21704, USA; Tel.: +1 7813252439 ; 
of treating chronic pain in the USA was placed at US\$635 billion annually [3]. This estimate included direct healthcare costs as well as lost productivity, and was indicated by the authors as a conservative estimate.

Pain as a medical issue puts a high demand on healthcare system resources. The current data indicate a shortage of primary care physicians in the USA, which is a problem that is reported to be exacerbated by the increase in federally mandated health insurance coverage, increasing the insured by approximately 30 million [4,5]. With pain being one of the most common reasons for patients to seek medical attention and also consuming a substantial amount of time in painrelated discussions during primary care visits [6], strategies that improve pain management that are safe and cost effective are desperately needed.

\section{Pain management analgesics}

Current conventional methods of pain management have a heavy reliance on analgesic drug therapy, and users often show little knowledge or concern of the risks associated with their use [7]. This reliance on drug therapy, often used as a monotherapy, has been proven to be inadequate and, in some instances, has been the cause of adding significant socioeconomic problems [8].

The over-the-counter (OTC) analgesics, acetaminophen and NSAIDs such as ibuprofen, are the most widely used medications. While these medications are generally thought to be safe, there is evidence that adverse side effects, which can be serious, occur especially with longterm use. NSAIDs are associated with a broad range of side effects, including renal toxicity [9], exacerbation of hypertension [10], fluid retention [11], gastrointestinal complications [12,13], cardiovascular events [14] and adverse effects on bone healing [15]. Approximately 107,000 patients are hospitalized annually for related gastrointestinal complications [16] due to the use of NSAIDs, and at least 16,500 NSAID-related deaths occur each year among arthritis patients alone in the USA [17]. This mortality figure does not include OTC NSAID drugs, so it is likely that the actual number is significantly greater. New risks have come to light with OTC pain medications. Epidemiological studies have shown that regular use of the analgesics acetaminophen and ibuprofen increases the risk of hearing loss both in men [18] and women [19] who used these pain medications. In addition, although therapeutic doses of acetaminophen are considered safe, studies suggest that acetaminophen overdosing is a regular occurrence [20]. At higher doses, acetaminophen can cause fatal liver damage and is responsible for approximately half of all cases of acute liver failure in the USA and the UK [21]. Another study of acetaminophen dosing indicates that hepatic injury linked to acetaminophen use is increasing significantly faster than population growth and acetaminophen product sales, indicating that a growing proportion of consumers are self-dosing acetaminophen beyond the toxic threshold [22]. The bottom line of all of these findings is that the extended use and misuse of OTC pain medications is a significant healthcare problem.

Opioid pain killer use for pain relief has rapidly escalated in the last two decades in the USA, and only recently have clinical, epidemiological and observational studies begun to evaluate their efficacy and effectiveness [23]. The results of these studies are mainly negative $[8,24]$. The wide adoption of opioids for workplace injury has recently been challenged, and reports suggest that strong opioids delay the return to work and increase compensation insurance costs. Due to their overuse, diversion and abuse, the number of deaths from painkillers quadrupled since 1999 according to federal data, leading the US FDA to consider the restriction of opioid medication use $[8,25]$.

It is now realized that interdisciplinary approaches to pain management, using both pharmacological and nonpharmacological methods, are beneficial for both acute and chronic pain [26-31]. Nonpharmacological methods for treating pain include acupuncture, chiropractic manipulation, behavioral modification and transcutaneous electrical nerve stimulation.

\section{Shortwave electromagnetic therapies}

Pulsed shortwave radiofrequency electromagnetic field therapy (termed pulsed electromagnetic field therapy, pulsed shortwave diathermy [PSWD] or pulsed radiofrequency energy therapy) has been shown to be an effective pain therapy that has the potential to impact current treatment options for a number of acute and chronic pain conditions [32-34]. This form of therapy is based on shortwave diathermy (SWD), which uses a shortwave radiofrequency, typically $27.12 \mathrm{MHz}$, in order to deliver an electromagnetic field into the target soft tissue. Initially, this approach was viewed as a highly effective heat therapy due to preferential 
absorption of the energy deep in the body's tissue [35]. Other electrical diathermy therapies that are in clinical use include microwave diathermy and ultrasound diathermy. Microwave diathermy uses radar waves that are of higher frequencies (434 and $915 \mathrm{MHz}$ ) than SWD and has a lower depth of penetration. Ultrasound diathermy employs high-frequency acoustic vibrations that are converted into heat in the body.

In the original form, continuous SWD had the potential to course thermal injury. To prevent excessive heat build-up, the signal was pulsed, which allowed heat to dissipate and the resulting therapy was still found to be therapeutic. This PSWD was labeled a nonthermal therapy as the level of heating was considered to be inadequate for it to be considered a thermal therapy. In the 1970s, the FDA required a sustained tissue heating of $41-45^{\circ} \mathrm{C}$ to be demonstrated in order for a treatment to be considered a thermal therapy [36], but clearly, PSWD can lead to substantial temperature increases depending on the energy input into the tissue [35]. Therefore, many PSWD treatments that were viewed as nonthermal therapies may actually have a thermal component [37]. SWD and PSWD are in wide use in clinical practice for both acute and chronic pain [38]. However, because of the multiple settings, the potential for thermal injury, and the high cost of many of these SWD and PSWD devices, this form of therapy is still restricted to clinical application by a trained technician. However, development and innovation of this form of electromagnetic field therapy has recently occurred. These new devices use a low, or very low, fixed pulsed signal that is well below the threshold for thermal injury. They often use a battery as a power source and deliver localized treatment with no far-field effects $[34,39]$. Having a low fixed output at a safe power level negates the danger of thermal injury and consequently the requirement of a trained technician. Therefore, these devices can now become a home-based, economical pain therapy, with the only requirements being the turning on and off of the device and the fixation of this low-powered device onto the target area of the body. To date, no serious side effects have been reported in clinical studies, further suggesting that these devices could be fully developed as home-use pain therapies.

Although these fixed, low-power devices are nonthermal therapies, they may have a very low thermal component as a consequence of the delivered energy. However, the temperature increases at this level are unlikely to cause the desired effects of heat therapy, namely higher tissue temperatures, which produces vasodilation, increasing the supply of oxygen and nutrients and the elimination of carbon dioxide and metabolic waste. By contrast, heat wrap therapy and the continuous application of heat for 8-12 h has been shown to be therapeutic in a number of studies [40,41]. The temperature increases with heat wraps has been reported to be $2^{\circ} \mathrm{C}$ at depths of $2 \mathrm{~cm}[40,42]$, which are clearly not achieved with low-dose PSWD devices. Therefore, the therapeutic effects of fixed, low-dose PSWD devices are most likely mediated through nonthermal effects.

\section{Clinical studies}

Extensive numbers of clinical studies have been performed using nonthermal PSWD over the last five decades for the treatment of acute and chronic pain $[32,33]$. More recently, clinical studies focusing on pain and edema, using smaller battery-powered devices, have demonstrated positive results for such targets as postoperative edema [43], postoperative pain [39,44,45], plantar fasciitis heel pain [46], pain from osteoarthritis of the knee [47], whiplash neck injury [48,49], delayed-onset muscle soreness [50], soft-tissue injuries [51] and chronic-wound healing [52,53]. These studies reported statistically significant decreases in pain and edema when compared with placebo treatments, confirming that lowpower PSWD is an effective pain therapy. Importantly, there have been no reported adverse side effects from these clinical studies. The clinical successes and safety of these devices are very positive indicators that small, home-use, pulsed electromagnetic field devices could be a viable option for pain management.

The data presented in these studies also demonstrates a decreased analgesic medication use. In the postoperative pain study by Rawe et al., significant decreases in narcotic pill use were reported $(\mathrm{p}=0.002)$, with patients in the study group using $50 \%$ fewer narcotic analgesics while experiencing $50 \%$ less pain in the 7 -day recovery period [39]. Two further postoperative pain studies reported significant decreases in narcotic medication use during the recovery period, as well as recording decreased pain scores [44,45]. One study reported a significant decrease at day $3(p=0.001)$, in the group treated with PSWD relative to the placebo group; this difference continued for the study period of 7 days [44]. 
The second study reported a significant 2.2-fold reduction in narcotic use in patients treated with PSWD at $48 \mathrm{~h}$ after surgery compared with placebo [45]. Other studies have also shown PSWD therapy to reduce the need for pain medication use in both acute and chronic orthopedic pain. During a 12 -week study on patients experiencing acute neck pain from whiplash injury, FoleyNolan et al. reported that subjects who received the PSWD therapy were consuming fewer analgesics by week 4 than placebo-controlled subjects [49]. In a study on the effects of PSWD therapy of heel pain from plantar fasciitis, there was a reported significant decline in pain after 7 days and a strong trend towards decreased pain medication use [46].

\section{Device parameters}

Clinical studies have used devices with different shortwave radiofrequencies, pulse rates, pulse widths and duty cycles. The different device parameters are shown in Table 1.

The published clinical data have shown that significant reductions in pain can be achieved with various device parameters. The consistency appears to be limited to the pulsed signal and that a shortwave radiofrequency is used by the devices, although different shortwave radiofrequencies have been employed. For example, a direct comparison of different device parameters can be made by looking at the Rawe et al. [39] and Heden and Pilla [44] studies. Both were double-blind, randomized and placebo-controlled studies that collected visual analog pain score and medication use data during the first 7 days of postoperative recovery from breast augmentation surgery. The data presented from both of these studies are comparable in that there was a significant decline in postoperative pain scores in the study group compared with the placebo control group, as well as significant reductions in narcotic medication

\begin{tabular}{|c|c|c|c|c|}
\hline $\begin{array}{l}\text { Shortwave } \\
\text { radiofrequency }(\mathrm{MHz})\end{array}$ & Pulse rate/s & Pulse width & Duty cycle (\%) & Ref. \\
\hline 27 & 450 & $60 \mu \mathrm{s}$ & 2.7 & {$[48,49]$} \\
\hline 27 & 1000 & $100 \mu \mathrm{s}$ & 10 & {$[39,43,46,50,52]$} \\
\hline 27 & 2 & $2 \mathrm{~ms}$ & 0.04 & {$[44,45]$} \\
\hline Not specified & 71 & $3.5 \mathrm{~ms}$ & 25 & [53] \\
\hline 6.8 & 2 & $7 \mathrm{~ms}$ & 1.4 & [47] \\
\hline 3,44 and 26 & 1000 and 900 & 73 and $100 \mu \mathrm{s}$ & 10 and 6.5 & [51] \\
\hline
\end{tabular}

use during the postoperative study period. This indicates that PSWD can be effective with a range of device parameters.

\section{Biological effects of nonthermal shortwave therapies}

Clinical studies have demonstrated PSWD therapy to be an effective pain therapy $[32,33]$. Moreover, there are indications that PSWD promotes tissue healing by reducing inflammation [34,51]. In vitro cell studies using gene arrays have demonstrated that PSWD treatment affects all phases of the wound healing cycle, including the inflammatory phase [54,55]. Expression of the inflammatory cytokine IL-1 $\beta$ has been shown to be significantly reduced in postoperative wound exudate in a human clinical study [45], as well as in a rat model of traumatic brain injury [56]. Moreover, cell, animal and clinical research has indicated that PSWD therapies elicit a healing response in tissue [51]. In a report by Kao et al., exposing wounds in diabetic mice to PSWD resulted in significantly increased dermal cell proliferation and collagen synthesis [57]. A number of animal studies have also shown improved healing responses to PSWD treatment [56,58,59]. Nonthermal pulsed electromagnetic fields have been reported to induce nitric oxide through a $\mathrm{Ca}^{2+} / c a l m o d u l i n$ signaling pathway [60]. Nitric oxide is a potent vasodilator, increasing blood flow and lymphatic drainage, promoting angiogenesis and upregulating growth factors, such as FGF-2. These effects could explain the positive effects on wound healing seen both in animal models and humans. Furthermore, cell studies suggest that the analgesic effect of PSWDs may be due to the increased expression of endogenous opioid peptide, as has been demonstrated in vitro by analysis of mRNA expression and opioid peptide levels in a cell culture system exposed to a PSWD [61]. In summary, pulsed shortwave radiofrequency therapies have shown biological responses that support its clinical use for the treatment of pain and soft-tissue healing.

\section{Conclusion \& future perspective}

Wider use and acceptance of this low-power shortwave technology has been slow in developing, in part due to the position of the FDA, which has maintained these devices in a class III category, a classification that is usually reserved for devices that are life-sustaining, life-supporting and are defined as those that pose a potentially unreasonable risk of illness 
or injury. By contrast, the higher-power clinicbased SWD/PSWDs are in a class II category. There are indications that a reclassification may be forthcoming, as a May 2013 adversary panel meeting recommended reclassification, but the discussion and recommendation was limited to postoperative pain and edema [101]. It is possible that high-quality clinical studies may be required by the FDA before giving these lowpower devices a new classification. With this noted, regulatory agencies in Canada and the EU, among others, have already classified such devices to be sold OTC.

The current research suggests that PSWD therapy reduces inflammation and promotes tissue healing, a feature that is a powerful argument for the therapy becoming widely available. By contrast, pharmacological approaches to pain management typically mask pain, cause adverse side effects and are contraindicated for a significant proportion of the population [62]. Modern fixed, low-power PSWDs do not suffer from these drawbacks. The clinical results confirm that PSWD therapy is an effective pain therapy that reduces the requirement of pain medications and, importantly, has shown no reported adverse side effects to date. The clinical success, the positive biological effects on soft tissue and the safety of these devices are very positive indicators that small, home-use PSWDs could be a viable adjunct option for pain management.

\section{Financial \& competing interests disclosure}

The author has no relevant affliations or financial involvement with any organization or entity with a financial interest in or financial conflict with the subject matter or materials discussed in the manuscript. This includes employment, consultancies, honoraria, stock ownership or options, expert testimony, grants or patents received or pending, or royalties.

No writing assistance was utilized in the production of this manuscript.

\section{References}

Papers of special note have been highlighted as:

- of interest

-. of considerable interest

1 Cheatle MD. Depression, chronic pain, and suicide by overdose: on the edge. Pain Med. 12(Suppl. 2), S43-S48 (2011).

2 Fishbain DA. The association of chronic pain and suicide. Semin. Clin. Neuropsychiatry 4(3), 221-227 (1999).

3 Gaskin DJ, Richard P. The economic costs of pain in the United States. J. Pain 13(8), 715-724 (2012).

4 Tobler L. A primary problem: more patients under federal health reform with fewer primary care doctors spell trouble. State Legis. 36(10), 20-24 (2010).

5 Green LV, Savin S, Lu Y. Primary care physician shortages could be eliminated through use of teams, nonphysicians, and electronic communication. Health Aff. (Millwood) 32(1), 11-19 (2013).

6 Henry SG, Eggly S. How much time do low-income patients and primary care physicians actually spend discussing pain? A direct observation study. J. Gen. Intern. Med. 27(7), 787-793 (2012).

7 Wilcox CM, Cryer B, Triadafilopoulos G. Patterns of use and public perception of over-the-counter pain relievers: focus on nonsteroidal antiinflammatory drugs. J. Rheumatol. 32(11), 2218-2224 (2005).

8 Alexander GC, Kruszewski SP, Webster DW. Rethinking opioid prescribing to protect patient safety and public health. JAMA 308(18), 1865-1866 (2012).

9 Murray MD, Brater DC. Renal toxicity of the nonsteroidal anti-inflammatory drugs. Annu. Rev. Pharmacol. Toxicol. 33, 435-465 (1993).

10 Forman JP, Rimm EB, Curhan GC. Frequency of analgesic use and risk of hypertension among men. Arch. Intern. Med. 167(4), 394-399 (2007).

11 Whelton A, Hamilton CW. Nonsteroidal anti-inflammatory drugs: effects on kidney function. J. Clin. Pharmacol. 31(7), 588-598 (1991).

12 Bjarnason I. Gastrointestinal safety of NSAIDs and over-the-counter analgesics. Int. J. Clin. Pract. Suppl. 178, 37-42 (2013).

13 Straube S, Tramer MR, Moore RA, Derry S, Mcquay HJ. Mortality with upper gastrointestinal bleeding and perforation: effects of time and NSAID use. $B M C$ Gastroenterol. 9, 41 (2009).

14 Gislason GH, Jacobsen S, Rasmussen JN et al. Risk of death or reinfarction associated with the use of selective cyclooxygenase-2 inhibitors and nonselective nonsteroidal antiinflammatory drugs after acute myocardial infarction. Circulation 113(25), 2906-2913 (2006).

15 van Esch RW, Kool MM, Van As S. NSAIDs can have adverse effects on bone healing. Med. Hypotheses 81(2), 343-346 (2013).

16 Singh G, Triadafilopoulos G. Epidemiology of NSAID induced gastrointestinal complications. J. Rheumatol. Suppl. 56, 18-24 (1999).
17 Wolfe MM, Lichtenstein DR, Singh G. Gastrointestinal toxicity of nonsteroidal antiinflammatory drugs. N. Engl. J. Med. 340(24), 1888-1899 (1999).

18 Curhan SG, Eavey R, Shargorodsky J, Curhan GC. Analgesic use and the risk of hearing loss in men. Am. J. Med. 123(3), 231-237 (2010).

19 Curhan SG, Shargorodsky J, Eavey R, Curhan GC. Analgesic use and the risk of hearing loss in women. Am. J. Epidemiol. 176(6), 544-554 (2012).

20 Wolf MS, King J, Jacobson K et al. Risk of unintentional overdose with non-prescription acetaminophen products. J. Gen. Intern. Med. 27(12), 1587-1593 (2012).

21 Hinson JA, Roberts DW, James LP. Mechanisms of acetaminophen-induced liver necrosis. Handb. Exp. Pharmacol. (196), 369-405 (2010).

22 Bond GR, Ho M, Woodward RW. Trends in hepatic injury associated with unintentional overdose of paracetamol (acetaminophen) in products with and without opioid: an analysis using the National Poison Data System of the American Association of Poison Control Centers, 2000-2007. Drug Saf. 35(2), 149-157 (2012).

23 Fields HL. The doctor's dilemma: opiate analgesics and chronic pain. Neuron 69(4), 591-594 (2011).

24 Alford DP. Chronic back pain with possible prescription opioid misuse. JAMA 309(9), 919-925 (2013). 
25 Kuehn BM. FDA committee: more restrictions needed on hydrocodone combination products. JAMA 309(9), 862 (2013).

26 Elvir-Lazo OL, White PF. The role of multimodal analgesia in pain management after ambulatory surgery. Curr. Opin. Anaesthesiol. 23(6), 697-703 (2010).

27 Elvir-Lazo OL, White PF. Postoperative pain management after ambulatory surgery: role of multimodal analgesia. Anesthesiol. Clin. 28(2), 217-224 (2010).

28 Holten KB, Veasey GD Sr. Managing chronic pain: what's the best approach? J. Fam. Pract. 57(12), 806-810 (2008).

29 Gagnon CM, Stanos SP, van der Ende G, Rader LR, Harden RN. Treatment outcomes for workers compensation patients in a US-based interdisciplinary pain management program. Pain Pract. 13(4), 282-288 (2013).

30 McCarberg BH, Stanos S, Williams DA. Comprehensive chronic pain management: improving physical and psychological function (CME multimedia activity). Am. J. Med. 125(6), S1 (2012).

31 Stanos S. Focused review of interdisciplinary pain rehabilitation programs for chronic pain management. Curr. Pain Headache Rep. 16(2), 147-152 (2012).

32 Guo L, Kubat NJ, Isenberg RA. Pulsed radio frequency energy (PRFE) use in human medical applications. Electromagn. Biol. Med. 30(1), 21-45 (2011).

- Excellent overview of the technology and the historical clinical studies using pulsed shortwave therapies and a very good introduction to the subject.

33 Guo L, Kubat NJ, Nelson TR, Isenberg RA. Meta-analysis of clinical efficacy of pulsed radio frequency energy treatment. Ann. Surg. 255(3), 457-467 (2012).

- Demonstrates the clinical benefit of shortwave therapies on wound healing, pain and edema.

34 Strauch B, Herman C, Dabb R, Ignarro LJ, Pilla AA. Evidence-based use of pulsed electromagnetic field therapy in clinical plastic surgery. Aesthet. Surg. J. 29(2), 135-143 (2009).

35 Draper DO, Knight K, Fujiwara T, Castel JC. Temperature change in human muscle during and after pulsed short-wave diathermy. J. Orthop. Sports Phys. Ther. 29(1), 13-18; discussion 19-22 (1999).

36 Guy AW, Lehmann JF, Stonebridge JB. Therapeutic applications of electromagnetic power. Proc. IEEE 62(1), 55-75 (1974).
37 Al-Mandeel MM, Watson T. The thermal and nonthermal effects of high and low doses of pulsed short wave therapy (PSWT). Physiother. Res. Int. 15(4), 199-211 (2010).

38 Shields N, Gormley J, O'Hare N. Short-wave diathermy: current clinical and safety practices. Physiother. Res. Int. 7(4), 191-202 (2002).

39 Rawe IM, Lowenstein A, Barcelo CR, Genecov DG. Control of postoperative pain with a wearable continuously operating pulsed radiofrequency energy device: a preliminary study. Aesthetic Plast. Surg. 36(2), 458-463 (2012).

- Demonstrates the use of pulsed shortwave therapies in reduced postoperative pain and the consequent requirement of narcotic medication use during the postoperative recovery period.

40 Draper DO, Hopkins TJ. Increased intramuscular and intracapsular temperature via ThermaCare Knee Wrap application. Med. Sci. Monit. 14(6), PI7-PI11 (2008).

41 Trowbridge CA, Draper DO, Feland JB, Jutte LS, Eggett DL. Paraspinal musculature and skin temperature changes: comparing the Thermacare HeatWrap, the Johnson \& Johnson Back Plaster, and the ABC Warme-Pflaster. J. Orthop. Sports Phys. Ther. 34(9), 549-558 (2004).

42 Song AS, Diller KR. Modeling heat shock protein expression produced by a heat wrap. J. Biomech. Eng. 131(7), 074510 (2009).

43 Nicolle FV, Bentall RM. Use of radio-frequency pulsed energy in the control of postoperative reaction in blepharoplasty. Aesthetic Plast. Surg. 6(3), 169-171 (1982).

44 Heden P, Pilla AA. Effects of pulsed electromagnetic fields on postoperative pain: a double-blind randomized pilot study in breast augmentation patients. Aesthetic Plast. Surg. 32(4), 660-666 (2008).

- Demonstrates the use of pulsed shortwave therapies in reducing postoperative pain and the consequent requirement of narcotic medication use during the postoperative recovery period.

45 Rohde C, Chiang A, Adipoju O, Casper D, Pilla AA. Effects of pulsed electromagnetic fields on interleukin-1 beta and postoperative pain: a double-blind, placebo-controlled, pilot study in breast reduction patients. Plast. Reconstr. Surg. 125(6), 1620-1629 (2010).

- Demonstrates the use of pulsed shortwave therapies in reducing postoperative pain and the consequent requirement of narcotic medication use during the postoperative recovery period.
46 Brook J, Dauphinee DM, Korpinen J, Rawe IM. Pulsed radiofrequency electromagnetic field therapy: a potential novel treatment of plantar fasciitis. J. Foot Ankle Surg. 51(3), 312-316 (2012).

47 Nelson FR, Zvirbulis R, Pilla AA. Non-invasive electromagnetic field therapy produces rapid and substantial pain reduction in early knee osteoarthritis: a randomized double-blind pilot study. Rheumatol. Int . 33(8), 2169-2173 (2013).

48 Foley-Nolan D, Barry C, Coughlan RJ, O'Connor P, Roden D. Pulsed high frequency $(27 \mathrm{MHz})$ electromagnetic therapy for persistent neck pain. A double blind, placebo-controlled study of 20 patients. Orthopedics 13(4), 445-451 (1990).

49 Foley-Nolan D, Moore K, Codd M, Barry C, O'Connor P, Coughlan RJ. Low energy high frequency pulsed electromagnetic therapy for acute whiplash injuries. A double blind randomized controlled study. Scand. J. Rehabil. Med. 24(1), 51-59 (1992).

50 Rasmussen CH, Rathleff MS, Knudsen CR et al. Pulsed electromagnetic field therapy reduces delayed onset muscle soreness in marathon runners. A doubleblind randomized placebo-controlled study. Presented at: The 13th EFORT Congress 2012. Berlin, Germany, 23-25 May 2012.

51 Bentall RHC. Low-level pulsed radiofrequency fields and the treatment of soft tissue injuries. Bioelectrochem. Bioenerg. 16, 531-548 (1986).

-. Contains some of the pioneering work on the beneficial effects of low-dose shortwave therapies on soft-tissue injury including wound tensile strength, wound healing rate, seconday wound healing and control of edema.

52 Rawe IM, Vlahovic TC. The use of a portable, wearable form of pulsed radio frequency electromagnetic energy device for the healing of recalcitrant ulcers: a case report. Int. Wound J. 9(3), 253-258 (2012).

53 Stiller MJ, Pak GH, Shupack JL, Thaler S, Kenny C, Jondreau L. A portable pulsed electromagnetic field (PEMF) device to enhance healing of recalcitrant venous ulcers: a double-blind, placebo-controlled clinical trial. Br. J. Dermatol. 127(2), 147-154 (1992).

54 Moffett J, Griffin NE, Ritz MC, George FR. Pulsed radio frequency energy field treatment of cells in culture results in increased expression of genes involved in the inflammation phase of lower extremity diabetic wound healing. J. Diabetic Foot Complications 2(3), 57-64 (2010). 
55 Moffett J, Kubat NJ, Griffin NE, Ritz MC, George FR. Pulsed radio frequency energy field treatment of cells in culture: increased expression of genes involved in angiogenesis and tissue remodeling during wound healing. J. Diabetic Foot Complications 3(2), 30-39 (2011).

56 Rasouli J, Lekhraj R, White NM et al. Attenuation of interleukin-1beta by pulsed electromagnetic fields after traumatic brain injury. Neurosci. Lett. 519(1), 4-8 (2012).

57 Kao HK, Li Q, Flynn B et al. Collagen synthesis modulated in wounds treated by pulsed radiofrequency energy. Plast. Reconstr. Surg. 131(4), 490e-498e (2013).

58 Strauch B, Patel MK, Navarro JA, Berdichevsky M, Yu HL, Pilla AA. Pulsed magnetic fields accelerate cutaneous wound healing in rats. Plast. Reconstr. Surg. 120(2), 425-430 (2007).

59 Strauch B, Patel MK, Rosen DJ, Mahadevia S, Brindzei N, Pilla AA. Pulsed magnetic field therapy increases tensile strength in a rat Achilles' tendon repair model. J. Hand Surg. Am. 31(7), 1131-1135 (2006).

60 Pilla AA. Nonthermal electromagnetic fields: from first messenger to therapeutic applications. Electromagn. Biol. Med. 32(2), 123-136 (2013).

61 Moffett J, Fray LM, Kubat NJ. Activation of endogenous opioid gene expression in human keratinocytes and fibroblasts by pulsed radiofrequency energy fields. J. Pain Res. 5 , 347-357 (2012).
62 O'Neil CK, Hanlon JT, Marcum ZA. Adverse effects of analgesics commonly used by older adults with osteoarthritis: focus on non-opioid and opioid analgesics. Am. J. Geriatr. Pharmacother. 10(6), 331-342 (2012).

\section{- Website}

101 US FDA 2013 Meeting Materials of the Orthopaedic and Rehabilitation Devices Panel.

www.fda.gov/AdvisoryCommittees/ CommitteesMeetingMaterials/ MedicalDevices/MedicalDevicesAdvisory Committee/OrthopaedicandRehabilitation DevicesPanel $/ \mathrm{ucm} 352525 \mathrm{htm}$ ?source= govdelivery 